\title{
INVESTIGATING THE ROLE OF STRUCTURAL FACTORS IN THE PERFORMANCE OF SMES BY USING STRUCTURAL EQUATIONS TECHNIQUE
}

\author{
Amir Abbas Rahmati Alaei', Younos Vakil Alroaia² \\ 1 Student of the Department of Management, Semnan Branch, Islamic Azad University, Semnan, Iran, e-mail: \\ Extraroyal@yahoo.com \\ 2 Department of Management, Semnan Branch, Islamic Azad University, Semnan, Iran, e-mail: y.vakil@ \\ semnaniau.ac.ir
}

Received: 2015.12.15

Accepted: 2016.02.01

Published: 2016.03.01

\begin{abstract}
Small and medium sized enterprises (SMEs) have plenty of competitive advantages compared to large companies. They are more capable of being original and innovative, and due to their flexibility, they can respond better to environmental changes and satisfy their customers' emerging needs. They also have more opportunities to redesign or alter and improve their management tools and information systems. Moreover, the employees can improve their expertise in novel fields. Due to the significance of SMEs in countries' economies, a great number of studies and investigations have been conducted on them. According to the previous studies of the researcher and review of the literature, relying on the three-dimensional model, three groups of structural, content, and environmental factors were identified as the most important factors affecting the performance of SMEs in Semnan province in Iran. Nevertheless, owing to the wide area of research and also in order to achieve better results, this study has focused only on investigating the role of structural factors in the performance of SMEs in Semnan province. The research method used in this study in terms of target is applied and in terms of data collection is analytical. The method used for data analysis is the technique of structural equations of second rank factor analysis. The results of the research revealed that structural factors affect SMEs performance to the amount of 3.99.
\end{abstract}

Keywords: small and medium sized enterprises, performance, structural equations technique, companies of industrial city in Semnan province.

\section{INTRODUCTION}

In Canada, $98 \%$ of enterprises are small and medium sized (SMEs), and in Japan $60 \%$ of industry exports belong to this kind of enterprises [7]. Although $99 \%$ of enterprises in Iran are small and medium sized, only $17 \%$ of industry valueadded tax belongs to them [10]. Various definitions of SMEs have been presented. In its report in 2003, UNIDO indicated that the definitions of SMEs in Iran are not in agreement, and different organizations and institutions have provided different definitions [15]. Azizi in a study entitled "Evaluating the factors affecting entrepreneur- ship in small and medium sized enterprises by using balanced reward cards" introduced the units with the personnel of below 150 people as small and medium sized enterprises [3].

The presence of deficiencies in the performance of small and medium sized enterprises especially structural deficiencies is evident. Therefore, the main issue in the present study concerns basically the question of which structural factors affect SMEs performance, and to what extent these factors affect SMEs performance. By determining the extent of effect of these factors, managers and policymakers are assisted in better recognition of damage and then by eliminat- 
ing the existing weaknesses in each index, we will help improve the performance of the active companies in small and medium sized industries. Ballantine illustrated that $11 \%$ of the SMEs set up one year ago and also $80 \%$ of the new SMEs set up five years ago experience failure [4]. Although setting up a successful SME in any segment of industry and trade is complicated, these challenges and problems are reduced by identifying the factors affecting positive or negative performance of small and medium industries. According to the report of Iran's small industries and industrial cities organization, about $90 \%$ of economic institutions in Iran are the ones with less than 50 [11].

Since structural factors have a fundamental role in SMEs performance and these factors are usually common among SMEs, investigating the role of each component of structural factors helps managers and entrepreneurs improve, reduce, or eliminate these factors in order to improve their performance. So by considering what was mentioned above, the significance of this study is evident because studying the role of each structural factor gives managers and policymakers a better understanding and helps them achieve a desirable performance along their purposes and strategies.

\section{LITERATURE OF THE REVIEW}

Karpak and Topcu utilized a network analysis process to prioritize the factors affecting the success of manufacturing SMEs in Turkey. According to the results of this research in which ANP has been used, rules and regulations are the most effective factor in the success of small enterprises [8]. Chorev and Anderson analyzed crucial factors of success of small newly formed enterprises possessing superior technology in Israel. According to the results of this research, the most important factors affecting the success of these enterprises include the commitment of management group, expertise, organization methods in general and marketing methods in particular, relation with customers, and managerial capabilities and research [6].

Also, Man et al. in a study reviewed the literature of SMEs success and showed that three features affect the success of these enterprises: endogenous factors, personal qualities, and entrepreneurs' personal qualities [9]. Rogoff et al. identified 11 factors affecting the success of small enterprises: personal qualities, managerial issues, financial affairs, marketing activities, human resources issues, economic conditions, product characteristics, competition, discipline, technology, and environmental factors [13]. In another study, Benzing et al. investigated the factors of success and failure of entrepreneurship in Turkey by utilizing factor analysis statistical method. According to the results of this research, entrepreneurs in Turkey believe that the popularity of the firm and its management including sincerity and social skills, previous experience and manager's character traits are the most important factors of success of small enterprises. Additionally, a complicated tax system and inability to absorb and keep reliable staff were mentioned as the most important problems of entrepreneurship [5]. Sepehrdoost and Kamran in an article entitled "The evaluation of technical efficiency of small industries in Hamedan province" mentioned that some reasons of developing countries' attention to small and medium industries compared to large ones are high flexibility, low cost investments, orientation towards target groups, and dynamic management in these kinds of industries which can create job opportunities, reduce poverty, improve income distribution, and meet basic needs as well as increase gross national product. The results obtained from the research showed that the average technical efficiency of the performance of small industries in the provinces of the country is $96 \%$ during the study. Analyzing the sensitivity of the factors affecting the efficiency proved that such factors as employment, value of investment, and products value have an important role in the improvement of efficiency of the country's small industries. The average efficiency of small industries in Hamedan province was obtained at $92 \%$ during the study and ranked 12 on average among the provinces of the country. Also, the analysis of efficiency index of all the production factors showed that the efficiency growth of small industries in the province does not have a positive and expected procedure [14].

Amin Aqae in an article entitled "The study of the factors affecting the performance of small industries from rural development experts' viewpoints" obtained the following results. The present situation of Iran's small rural industries is not able to justify extra staff in agricultural section, significant difference of welfare level between villages and cities, not immigration of villagers to big cities, and economic and social development in Iran's villages. The study of the factors 
affecting the performance of Iran's small rural industries can clarify some important points concerning the reasons of lack of agreement between Iran's small rural industries and rural development goals and clarify basic planning lines of enterprises managers and government policymakers. The factors affecting the performance of Iran's small rural industries have been categorized into three groups, namely structural, environmental and content factors. Then by utilizing the descriptive-quantitative method, Iran's rural development experts' viewpoints are studied regarding the extent to which each factor affects the performance of small rural industries and then each factor is ranked [1].

Aminbeidokhti and Zargar in an article entitled "The study of existing obstacles to SMEs development and presentation of a framework supporting them" maintain that SMEs in Semnan province have encountered various endogenous and exogenous obstacles and problems. Besides, the results of the statistical analyses showed that facilities and financial and nonfinancial supports from SMEs have not been sufficient in financial, technical, marketing, and executive fields [2]. Piri et al. indicated that the purpose of this research was to study the direct and indirect effects of competitive industrial forces on adopting strategies and performance of small and medium industries in industrial cities and areas in Hamedan province that was tested by 3 hypotheses. The method of this research is applied based on the purpose of research, but in terms of procedure and nature, it is a causative research. The population of study, i.e. the managers of manufacturing companies of industrial cities and areas in Hamedan province, is 501 people. In this research, a questionnaire was designed to collect data, and after testing its validity and reliability, it was given to the sample including 273 managers employed in manufacturing companies of industrial cities and areas in Hamedan province. Data analysis in this research is carried out by utilizing modeling techniques of structural equations with the software LISREL. The research findings confirm the moderating role of managers' performance by adopting strategies and show that the managers of small and medium industries can moderate some of the negative effects of competitive industrial forces by adopting appropriate strategies in production, study of environment, and adjusting decision-making. This research also indicates that the managers' performance can be assessed by comparing direct and indirect effects of competitive industrial forces on performance. The obtained results of this research confirm the moderating role in the performance of managers of industrial units in Hamedan province by adopting an appropriate strategy [12].

\section{METHODOLOGY}

This research is applied in terms of purpose and descriptive in procedure. It was conducted in companies located in industrial cities in Semnan province in 2014. The main purpose of the pres-

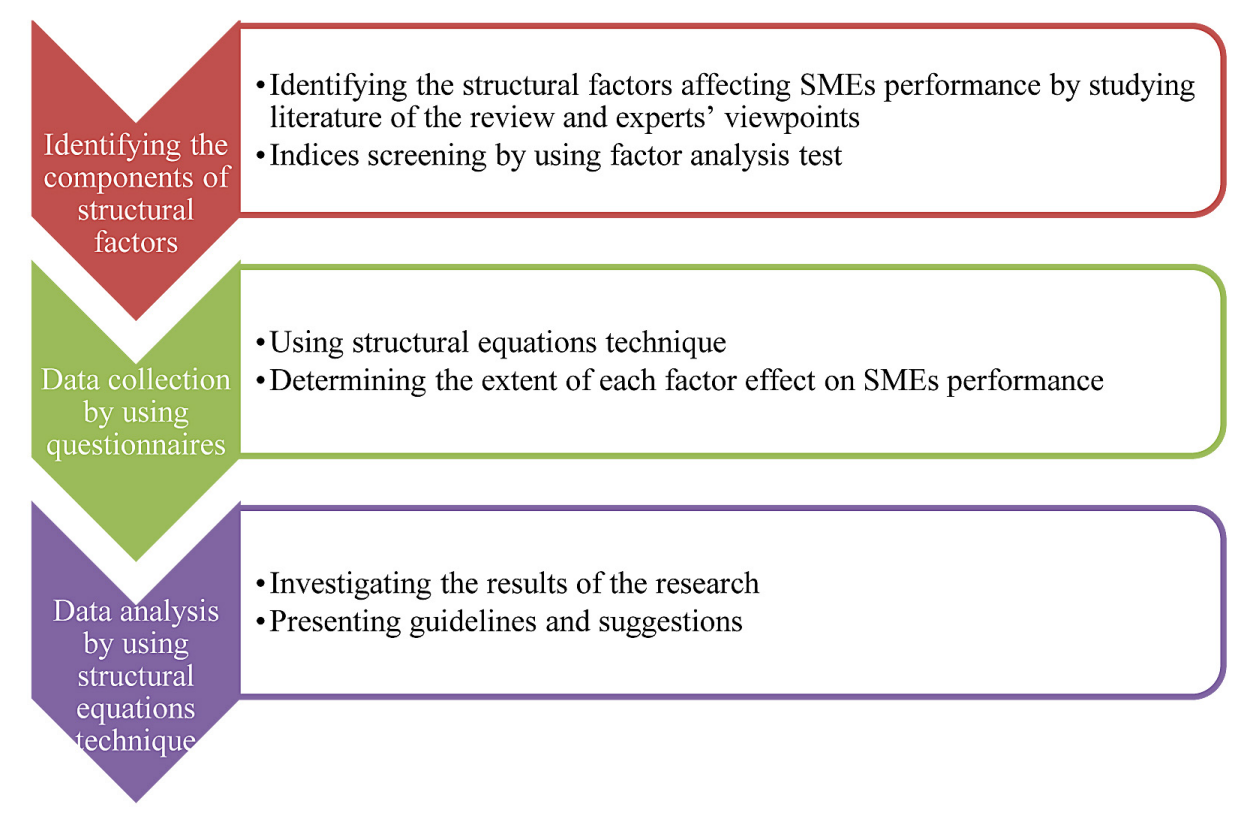

Fig. 1. The phases of conducting the research 
ent research is investigating the role of structural factors in the performance of small and medium industries of Semnan province. For this reason, first with the help of experts' viewpoints and also studying the literature of the review, the components of structural factors were identified and then refined by using factor analysis test and eventually 4 main components were identified. Then the extent of effect of these four components and finally the total effect of structural factors on SMEs performance were identified by using structural equations technique.

\section{DATA ANALYSIS}

By studying the literature of the review and experts' viewpoints, the following factors were identified as the main components of structural factors affecting SMEs performance.

Table 1. The components of structural factors affecting SMEs performance obtained from literature of the review and statistical investigations and experts' viewpoints

\begin{tabular}{|c|l|}
\hline Row & \multicolumn{1}{|c|}{ Structural factors } \\
\hline 1 & The amount of capital \\
\hline 2 & The amount of demand for products \\
\hline 3 & $\begin{array}{l}\text { The amount of financial resources to guarantee } \\
\text { contracts }\end{array}$ \\
\hline 4 & The amount of availability of efficient technology \\
\hline 5 & $\begin{array}{l}\text { Condition of machinery of small and medium } \\
\text { manufacturing units }\end{array}$ \\
\hline 6 & Marketing and sales costs \\
\hline 7 & Financial facilities \\
\hline 8 & Affiliating to larger enterprises \\
\hline 9 & Fluctuations in raw materials costs \\
\hline 10 & Amount of availability of raw materials \\
\hline
\end{tabular}

Table 2. The main components selected by factor analysis test and SPSS software

\begin{tabular}{|c|l|}
\hline Row & \multicolumn{1}{|c|}{ Structural factors } \\
\hline 1 & The amount of capital \\
\hline 2 & The amount of demand for products \\
\hline 3 & $\begin{array}{l}\text { The amount of financial resources to guarantee } \\
\text { contracts }\end{array}$ \\
\hline 4 & The amount of availability of efficient technology \\
\hline
\end{tabular}

\section{Conceptual model of research}

In this study, structural factors are an independent variable and SMEs performance is a dependent variable. By considering experts' viewpoints and studying literature of the review and the result of factor analysis test by using SPSS software and indices screening, the following conceptual model was obtained (Figure 2).

\section{The phases of data analysis by using structural equations technique (factor analysis)}

Prior to carrying out factor analysis, sampling adequacy test must be conducted in order to make sure of sampling adequacy. To determine this, two categories of Bartlett and Kaiser measures (KMO) are used. The value of KMO test varies between 0 and 1 . If the value of KMO is less than 0.50 , the data will not be suitable for factor analysis. If its value is between 0.50 and 0.69 , then the data must be analyzed carefully. But if its value is equal to or more than 0.7 , the correlations between data are suitable for factor analysis. Bartlett tests the hypothesis that the observed matrix of correlations belongs to a population with dependent variables. If the hypothesis that the variables are not correlated is rejected (level of significance is 0.05 and less than that), the data are suitable

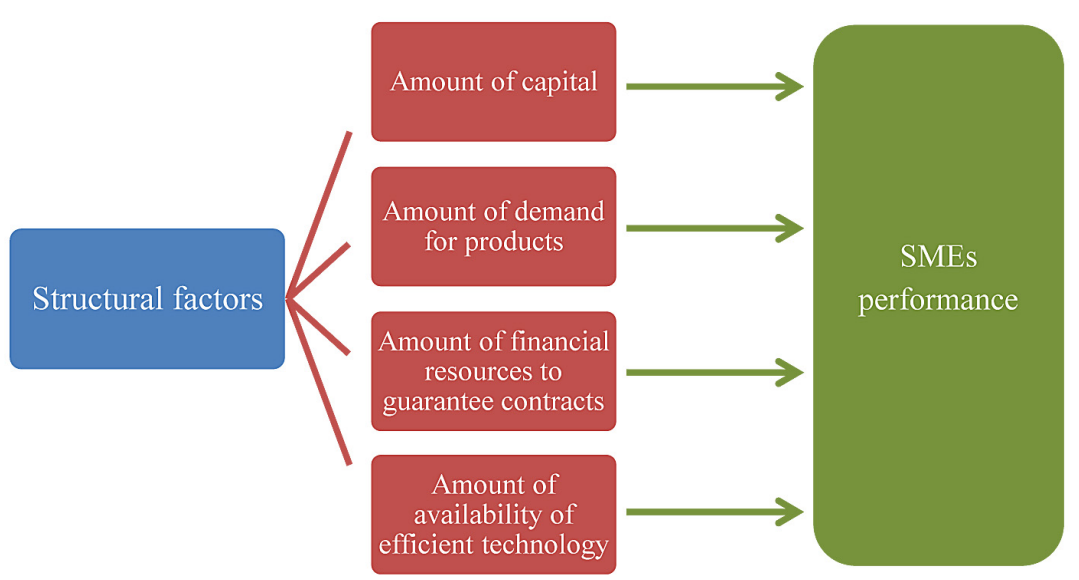

Fig. 2. Conceptual model of research 
for factor analysis, otherwise factor analysis must not be used.

As is observed in Table 3, the value of KMO test is 0.84 and the level of the significance of Bartlett test is zero. Both of them show that the data are suitable for factor analysis. In this phase, in order to investigate the significance of research model, answer research questions, and examine research hypotheses, structural equations technique of factor analysis model was used. First, in Table 4 we will introduce abbreviations of components used in this software.

In Figure 4, structural equations model of standard coefficients (factor weights) was shown for research components obtained by means of Amos software.

Factor weight is a value between zero and one. If factor weight is less than 0.03 , the relation is considered weak and so it is ignored. The factor weight between 0.03 and 0.06 is acceptable and if it is greater than 0.06 , it is highly desirable.

Here the variable of the amount of availability of technology with 0.01 has the weakest relation with SMEs performance. Since its value is less than 0.3 , we will remove it from the model and in the factor analysis of second rank we will

Table 3. The results of Kaiser and Bartlett tests

\begin{tabular}{|l|l|l|}
\hline The value of KMO test & 0.84 & $\begin{array}{l}\text { It is greater than } 0.70, \text { so } \\
\text { the data are suitable for } \\
\text { factor analysis }\end{array}$ \\
\hline $\begin{array}{l}\text { The level of significance } \\
\text { of Bartlett test }\end{array}$ & 0.00 & $\begin{array}{l}\text { It is less than } 0.05, \text { so the } \\
\text { variables are correlated } \\
\text { and suitable for factor } \\
\text { analysis }\end{array}$ \\
\hline
\end{tabular}

Table 4. Abbreviations used in the software

\begin{tabular}{|l|c|}
\hline \multicolumn{1}{|c|}{ Component } & Abbreviation \\
\hline Amount of demand for production & MM \\
\hline Amount of availability of technology & MF \\
\hline Amount of financial resources & MH \\
\hline Amount of capital & MS \\
\hline SMEs performance & PROBLEMS \\
\hline
\end{tabular}

Table 5. Interpretation of significance of factor weights of variables of research model

\begin{tabular}{|c|l|c|}
\hline Row & \multicolumn{1}{|c|}{ Variable } & $\begin{array}{c}\text { Value } \\
\text { of factor } \\
\text { weight }\end{array}$ \\
\hline 1 & Amount of capital (MS) & 1.01 \\
\hline 2 & Amount of demand for production (MM) & 1.00 \\
\hline 3 & Amount of financial resources (MH) & 0.58 \\
\hline 4 & Amount of availability of technology (MF) & 0.01 \\
\hline
\end{tabular}

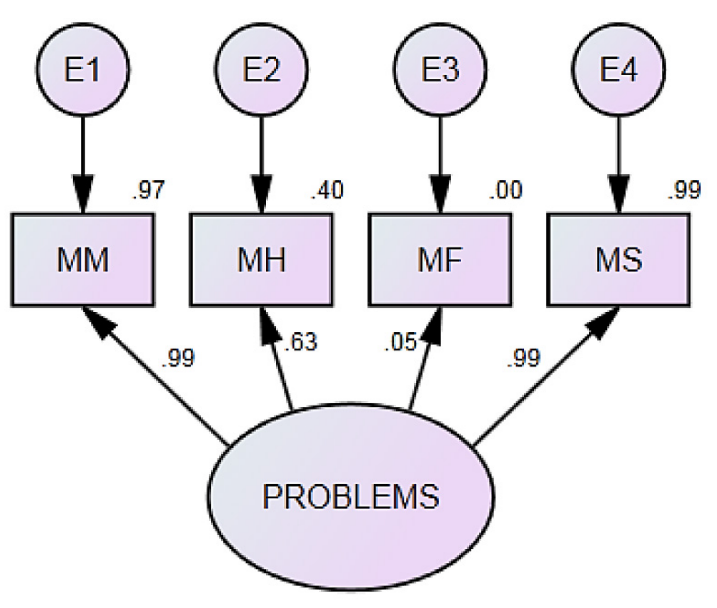

Fig. 3. Degree of dependence of research variables in factor analysis of first rank

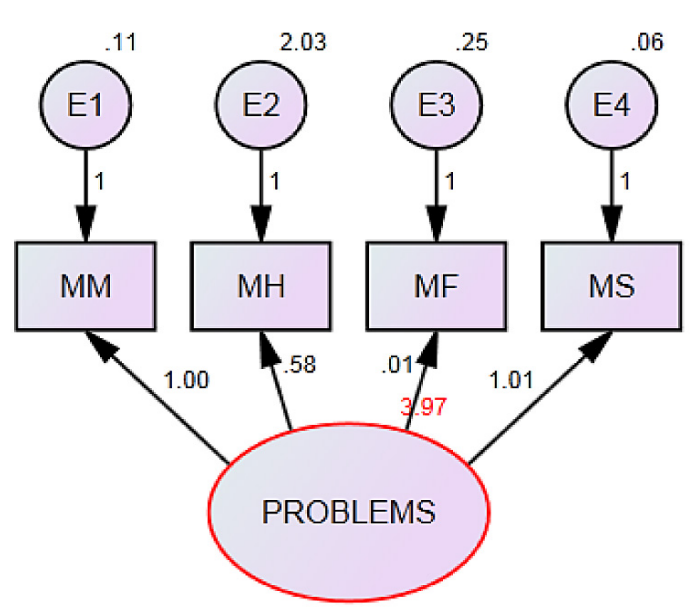

Fig. 4. Structural equations model of components of structural factors

show the extent of effect of the other three factors in the model. The rest of the variables have very strong relations with the hidden variable of SMEs performance.

\section{Factor analysis of second rank}

In Figure 5, the output of standard coefficients for the components of structural factors has been shown by using three components of the amount of capital, the amount of demand for production, and the amount of financial resources to guarantee contracts and eliminating the component of amount of availability of technology. As is seen, in the standard output (that is, by considering amount of error), the amount of capital and the amount of demand for production are related to SMEs performance with the same extent of 0.063 . Now with the help of nonstandard output of Amos software (Figure 6), we will investigate the level of significance of factor weights. 


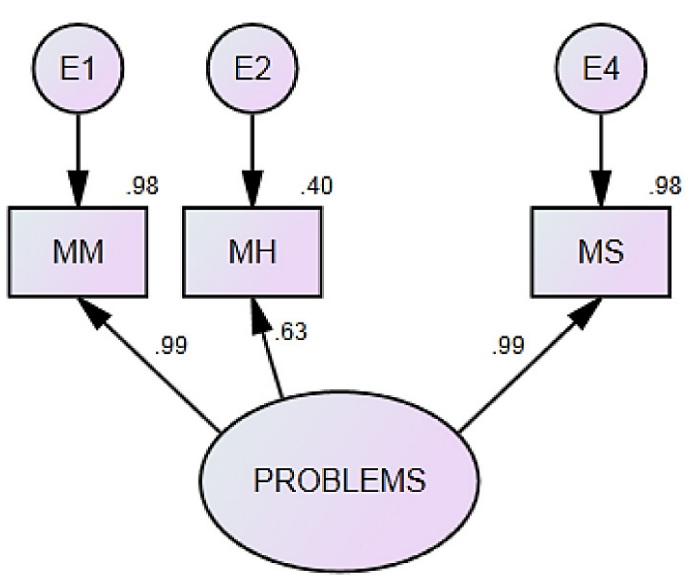

Fig. 5. The extent of dependence of research variables in factor analysis of second rank (standard output)

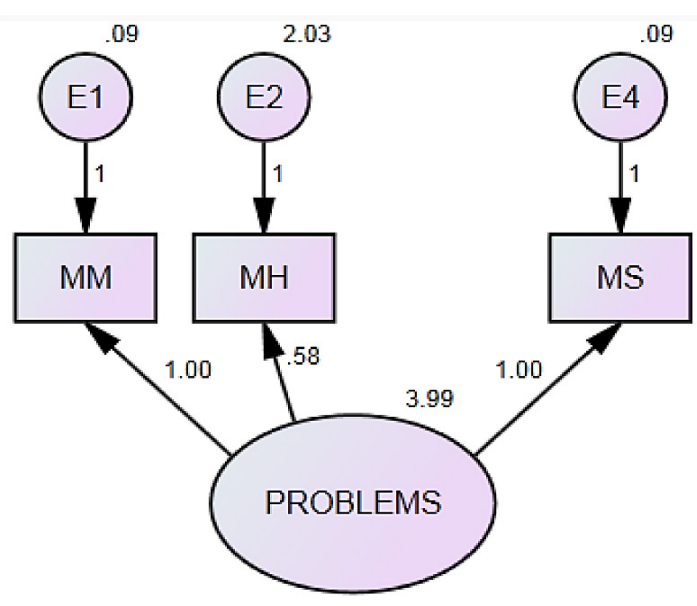

Fig. 6. Structural equations model, factor analysis of the second rank (Coefficients of significance)

Table 6. Interpretation of significance of factor weights of research variables in factor analysis of the second rank

\begin{tabular}{|c|l|c|l|}
\hline Row & \multicolumn{1}{|c|}{ Variable } & Value of factor weight & Interpretation \\
\hline 1 & Amount of capital $(\mathrm{MS})$ & 1.00 & It is greater than 0.5 , so level of significance is strong \\
\hline 2 & Amount of demand for production $(\mathrm{MM})$ & 1.00 & It is greater than 0.5 , so level of significance is strong \\
\hline 3 & Amount of financial resources $(\mathrm{MH})$ & 0.58 & It is greater than 0.5 , so level of significance is strong \\
\hline
\end{tabular}

In Table 6, we will investigate the amount of factor weight of each of the components.

Here all the factors have very strong relations with the hidden variable of SMEs performance, but the components of the amount of capital and demand for production have strong relations and component of amount of availability of financial resources has a medium relation with SMEs performance. As is seen, these three factors affect SMEs performance with the extent of 3.99 altogether.

As evident, by eliminating the variable of amount of availability of technology, the extent of dependence of the other three factors has increased to the extent of 0.02 . In order to investigate the significance of relations between variables in factor analysis of the second rank, t-test statistic or t-value is used. Since significance is examined in 0.05 level of error, the relation is not significant if the amount of the factor weights obtained from tvalue test is smaller than the critical value of 1.96 .

\section{RESULTS}

In this section, the significance of the model obtained values is examined. Since in this research we try to test the hypotheses in the level of confidence of 0.95 or error level of 0.05 , it is significant if the value of $t$-test is between -1.96 and +1.96 .
Major hypothesis. The components of structural factors (amount of capital, demand for production, and amount of availability of financial resources) have a significant effect on SMEs performance (Table 7).

Also in Table 8, CR is the same as statistic. If it is higher than 1.96, it shows that the relation is significant. It is seen in this table that CR of all the factors is higher than 1.96. It means that all factors have a significant dependence with SMEs performance. In other words, the amount of capital and the amount of demand for production affect SMEs performance to the extent of 14.22 and the amount of financial resources affect it to the extent of 3.77 .

The result of testing the first minor hypothesis - amount of capital has a significant effect on SMEs performance (Table 9).

The result of testing the second minor hypothesis - amount of demand for production has a significant effect on SMEs performance (Table 10).

The result of testing the third minor hypothesis - the amount of availability of financial resources to guarantee contracts has a significant effect on SMEs performance (Table 11).

Evaluating fitting of model of factor analysis of second rank - as is seen in Table 10, the model has a good fitting. 
Table 7. Testing the major hypothesis of the research

\begin{tabular}{|l|c|c|c|c|}
\hline From & On & $\begin{array}{c}\text { Standardized } \\
\text { coefficient }\end{array}$ & Figures of significance $(\mathrm{t})$ & $\begin{array}{c}\text { Confirm or reject the } \\
\text { hypothesis }\end{array}$ \\
\hline $\begin{array}{l}\text { Components of } \\
\text { structural factors }\end{array}$ & SMEs performance & 3.99 & $>1.96$ & confirm \\
\hline
\end{tabular}

Table 8. Amount of statistic of C.R (statistic of $t$ for all factors)

\begin{tabular}{|l|c|l|}
\hline \multicolumn{1}{|c|}{ Having significant dependence<1.96 } & Value of statistic of CR & \multicolumn{1}{|c|}{ Variable } \\
\hline The relation is significant & 14.22 & Amount of capital \\
\hline The relation is significant & 14.22 & Amount of demand for production \\
\hline The relation is significant & 3.77 & Amount of availability of financial resources \\
\hline
\end{tabular}

Table 9. Testing the first minor hypothesis of the research

\begin{tabular}{|c|c|c|c|}
\hline From & On & Component coefficient & Figures of significance (t) \\
\hline Component of amount of capital & SMEs performance & 14.22 & Greater than 1.96 \\
\hline
\end{tabular}

Table 10. Testing the second minor hypothesis of the research

\begin{tabular}{|c|c|c|c|}
\hline From & On & Component coefficient & Figures of significance (t) \\
\hline Component of amount of demand for production & SMEs performance & 14.22 & Greater than 1.96 \\
\hline
\end{tabular}

Table. 11. Testing the third minor hypothesis of the research

\begin{tabular}{|c|c|c|c|}
\hline \multicolumn{1}{|c|}{ From } & On & Component coefficient & Figures of significance $(\mathrm{t})$ \\
\hline $\begin{array}{l}\text { Component of amount of availability of } \\
\text { financial resources }\end{array}$ & SMEs performance & 3.77 & Greater than 1.96 \\
\hline
\end{tabular}

Table. 12. Testing the fitting of model of factor analysis of second rank

\begin{tabular}{|l|c|c|}
\hline \multicolumn{1}{|c|}{ Fitting index } & Acceptability criterion & Statistic of model of effect indices \\
\hline RMSEA (testing deviation of each degree of freedom) & $0.08>$ RMSEA & 1.085 \\
\hline GFI (fitting index) & $0.90<\mathrm{GFI}$ & 1.00 \\
\hline CFI (comparative fitting index) & $0.90<\mathrm{CFI}$ & 1.00 \\
\hline CMIN (Chi-square fitting index) & $1<\mathrm{CMIN}<5$ & 1.04 \\
\hline PRATIO (fitting index of economics ratio) & $1>$ PRATIO & 0.00 \\
\hline
\end{tabular}

\section{DISCUSSION}

According to the results of the research by Karpak and Topcu in which ANP has been used, rules and regulations are the most effective factor in the success of small enterprises. But in the present research, the amount of capital and the amount of demand for production have the greatest effect on SMEs performance. Rogoff identified 11 factors affecting the success of small enterprises: personal qualities, managerial issues, financial affairs, marketing activities, human resources issues, economic conditions, product characteristics, competition, discipline, technology, and environmental factors. In our research, we concluded that financial affairs such as the amount of capital and availability of financial resources affect SMEs performance.

The results obtained from the research by Sepehrdoost and Kamran revealed that such factors as employment, value of investment, and products value have an important role in the improvement of efficiency of the country's small industries. In our research, we achieved similar results. We concluded that such factors as the size of demand for production and investment affect SMEs performance. Amin Aqae has classified the factors affecting performance of Iran's small rural industries into three groups of structural, content, and environmental factors. We also emphasized the role of structural factors in SMEs performance. Aminbeidkhti and Zargar in their research showed 
that facilities and financial and nonfinancial supports from SMEs have not been sufficient in financial, technical, marketing, and executive fields. And financial affairs affect SMEs performance.

\section{CONCLUSIONS}

In the present research, after ten main components of structural factors affecting SMEs performance were identified by studying literature of the review and experts' viewpoints, we recognized four main factors of the amount of capital, the size of demand for production, availability of financial resources andtechnology by means of factor analysis test. Then according to the results of structural equations technique and factor analysis of first rank, the availability of technology was eliminated, and in factor analysis of second rank, we concluded that components of structural factors (amount of capital, demand for production, and the availability of financial resources) affect SMEs (companies of industrial city in Semnan province in Iran) performance with the extent of 3.99 totally. Since the demand for production is one of the factors affecting SMEs performance, it is suggested that enterprises use this factor to improve their performance through factors of marketing and management of marketing and proper and novel sales.

On the other hand, due to the effect of the amount of capital and amount of financial resources to guarantee contracts on SMEs performance, it is suggested that companies improve this factor in order to improve their performance by using funding tools, such as different kinds of loans and also cooperation with banks and financial institutions.

\section{REFERENCES}

1. Amin Aqae M., 2008. Study of factors affecting performance of small industries from rural development experts' viewpoints. Village and Development, 11(4), 125-146.

2. Aminbeidokhti A., Zargar M., 2011. Study of existing obstacles to SMEs development and presentation of a framework supporting them. Cultural, economic, social, and scientific monthly publication of work and society, issue 138.

3. Azizi M., Vakilalroaya Y., Tavangar A., 2012. Evaluation of the factors affecting entrepreneurship in small and medium companies by utilizing balanced reward cards. Case study: Semnan's industrial city.
National conference of entrepreneurship and management of knowledge-based enterprises. Sari.

4. Ballantine J., Levy M., Powell P. 1998. Evaluating information systems in small and medium-sized enterprises: issues and evidence. European Journal of Information Systems, 7(4), 241-255.

5. Benzing C., Chu H.M., Kara O. 2009. Entrepreneurs in Turkey: A factor analysis of motivations, success factors, and problems. Journal of Small Business Management, 47(1), 58-91.

6. Chorev S. and Anderson A.R. 2006. Success in Israeli high-tech start-ups; critical factors and process. Technovation, 26(2), 162-174.

7. Halabisky D. 2006.The growth process in firms: job creation by firm age, small business policy branch industry. Canada.

8. Karpak B. and Topcu I. 2010. Small medium manufacturing enterprises in Turkey: Ananalytic network process frame work for prioritizing factors affecting success. Int. J. Production Economics, $125,60-70$.

9. Man T.W., Lau T., Chan K.F. 2002. The competitiveness of small and medium enterprises: A conceptualization with focus on entrepreneurial competencies. Journal of Business Venturing, 17, 123-142.

10. Nasehifar V., Saadat M., Masoumzadeh Zavvareh A., Ahmadi M., 2010. Strategies and policies in support of institutions of marketing services. Journal Commercial Research Publication, 55, 109-150.

11. Organization of small industries and industrial cities, 2011. Successful policies in development of small industries in 20 industrial and developing countries. Tehran: publications of organization of Iran's small industries.

12. Piri A., Safaeshakib A., Hosseinzadeh A., 2013. Evaluation of performance of managers of manufacturing companies in response to competitive industrial forces in SMEs (Case study: Industrial cities and areas in Hamedan province). Conference of Management, Challenges and Guidelines, Shiraz, 2013.

13. Rogoff E.G., Lee M.S., Suh D.C. 2004. Who done it? Attributions by entrepreneurs and experts of the factors that cause and impede small business success. Journal of Small Business Management, 42(4), 364-376

14. Sepehrdoost H., Kamran N. 2012. Evaluation of technical efficiency of small industries in Hamedan province, 4(4), 147-174.

15. UNIDO 2003. Strategy of Increase in effective and competitive participation in small and medium industries in economy and industry of Islamic Republic of Iran. Translator: Abdoreza Sheghaghi and Masood Shafie (2004), 1st ed., Cultural Institution of Rasa, Tehran. 